\title{
Estudo fitoquímico e Alelopático do Extrato de Caule de SUCUPIRA-BRANCA (Pterodon emarginatus) ${ }^{1}$
}

\author{
Phytochemistry and Allelophatic Study of Pterodon emarginatus Stem Extract
}

\author{
HERNÁNDEZ-TERRONES, M.G. ${ }^{2}$, MORAIS, S.A.L. ${ }^{3}$, FERREIRA, S. ${ }^{4}$, SANTOS, D.Q. ${ }^{5}$, \\ NASCIMENTO, E.A. ${ }^{6}$ e CHANG, R. $^{7}$
}

\begin{abstract}
RESUMO - A alelopatia é um dos fenômenos pouco estudados no Cerrado. Trata-se de uma ocorrência natural, resultante da liberação de substâncias capazes de estimular ou inibir o desenvolvimento de outras plantas. Objetivou-se neste trabalho avaliar a ação alelopática de extratos da sucupira-branca (Pterodon emarginatus) sobre a germinação e o desenvolvimento da raiz e parte aérea do capim-colonião (Panicum maximum). Bioensaios de germinação realizados em placas de Petri comprovaram que o extrato metanólico do tronco dessa planta, a $150 \mathrm{ppm}$, inibiu 83\% do desenvolvimento da raiz, 75\% da parte aérea e 30\% da germinação de sementes de capim-colonião. Em casa de vegetação, os resultados de inibição foram de $83 \%$ para a parte aérea, $80 \%$ para a raiz e $63 \%$ para a germinação, mas somente na concentração de 400 ppm. Frações do extrato metanólico bruto obtidas por cromatografia de coluna cromatográfica não reproduziram os resultados de inibição obtidos inicialmente. A fração mais ativa (diclorometano/clorofórmio) foi analisada por CG/EM. Ela é constituída fundamentalmente por substâncias alifáticas de cadeia longa: fitol (13,5\%), ácido oléico $(12,8 \%)$, linoleiladato de metila $(10,9 \%)$ e ácido palmítico $(6,9 \%)$. Foram detectados, também, os compostos 1,2,4-trimetil e isopropilbenzenos $(12,2 \%)$ e as cetonas isoméricas isopropenilmetilcetona e 3-penten-2-ona (7,3\%). Três compostos desconhecidos também se destacaram: um de baixa massa molar (98 $\mathrm{Da}, 13,5 \%$ ) e dois de massa molar elevada $(13,6 \%)$.
\end{abstract}

Palavras-chave: atividade alelopática, compostos voláteis, extrato metanólico.

\begin{abstract}
Allelopathy is one of the natural phenomena little studied in the cerrado. It is the result of the release of substances capable of stimulating or inhibiting the growth of other plants. The objective of this work was to evaluate the allelophatic action of the white sucupira Pterodon emarginatus) stem extract on the germination and development of colonião grass (Panicum maximum) under germination, root and aerial part development of colonião grass (Panicum maximum) root and aerial part. Germination assays carried out in Petri dishes confirmed that the methanolic (200 ppm) extract inhibited the growth of hypocotyl (75\%), root (83\%), and germination (30\%) of colonião grass. The greenhouse results obtained were: hypocotyl $83 \%$, root $80 \%$ and germination 63\%, but at a concentration of $400 \mathrm{ppm}$. Methanolic extract fractions did not reproduce the results cited above. The most active fraction (dichloromethane/chloroform) was analyzed by GC/MS. It contains mainly long-chain aliphatic compounds such as phytol (13.5\%), oleic acid
\end{abstract}

1 Recebido para publicação em 27.2.2007 e na forma revisada em 25.10.2007.

2 Prof. Associado I do Instituto de Química - Universidade Federal de Uberlândia, Avenida João Naves de Ávila, 2121, UberlândiaMG, 38408-100, <mhernandez@iqufu.ufu.br>; ${ }^{3}$ Prof. Associado I do Instituto de Química - Universidade Federal de Uberlândia, Avenida João Naves de Ávila, 2121, Uberlândia-MG, 38408-100, <salemos@ufu.br>; ${ }^{4}$ Mestre pelo Instituto de Química Universidade Federal de Uberlândia, Avenida João Naves de Ávila, 2121, Uberlândia-MG, 38408-100; ${ }^{5}$ Prof. Substituto do Instituto de Química - Universidade Federal de Uberlândia, Avenida João Naves de Ávila, 2121, Uberlândia-MG, 38408-100, <químicodouglas@yahoo.com.br>, Mestre pelo Instituto de Química - Universidade Federal de Uberlândia; ${ }^{6}$ Prof. Titular Aposentado e Pesquisador Voluntário do Instituto de Química - Universidade Federal de Uberlândia, Avenida João Naves de Ávila, 2121, Uberlândia-MG, 38408-100, <eanascimeto@ufu.br>; 7 Pesquisador Substituto I do Instituto de Química - Universidade Federal de Uberlândia, Avenida João Naves de Ávila, 2121, Uberlândia-MG, 38408-100, <chang@iqufu.ufu.br>.

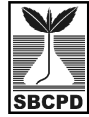

Planta Daninha, Viçosa-MG v. 25, n. 4, p. 755-762, 2007 
(12.8\%), methyllinolelaidate (10.9\%) and palmitic acid (6.9\%); 1,2,4-trimethyl-andisopropenylbenzene (12.2\%); two isomeric ketones (isopropenyl methyl and 3-penten-2-one) (7.3\%) were also detected. Three unknown compounds were also important: one with a low molecular weight (98 Da, 13.5\%) and two of high molecular weight (13.6\%).

Keywords: allelopathic activity, volatile extractives, methanolic extract.

\section{INTRODUÇÃO}

O termo alelopatia é definido como qualquer efeito causado por uma planta, ou microrganismos, sobre outras plantas, por meio de compostos químicos lançados no meio ambiente. Esses compostos são conhecidos como aleloquímicos ou agentes aleloquimicos (Putnam \& Duke, 1978; Rice, 1984).

O conceito de alelopatia se distingue em tese, com nitidez, do de competição, que ocorre pela redução ou remoção do ambiente de um fator de crescimento necessário a ambas as plantas que vegetam no mesmo habitat, como água, luz ou substâncias minerais, enquanto a alelopatia ocorre pela adição de substâncias químicas ao ambiente (Rice, 1984). Contudo, no campo, é muito dificil separar os fenômenos de interferência: alelopatia e competição. Alguns efeitos são mais expressivos do que outros, podendo ser diagnosticados com mais clareza. No entanto, substâncias químicas diferentes podem apresentar algumas semelhanças na inibição dos diversos estádios de desenvolvimento de uma planta (Buss et al., 2003; Chon et al., 2005).

O mecanismo de ação das substâncias alelopáticas sobre outras plantas não é totalmente conhecido (Rice, 1984). Alguns autores afirmam que os aleloquimicos interferem no metabolismo, reduzindo a oferta de energia e, conseqüentemente, impedindo o desenvolvimento normal desses organismos. Pesquisas têm demonstrado que a interferência dos aleloquímicos ocorre com freqüência na assimilação de nutrientes, na inibição da fotossintese (Einhellig et al., 1993; Tawaha et al., 2003; Anaya et al., 2005), na respiração (Neave \& Dawson, 1989), na sintese de proteínas, na permeabilidade da membrana celular e em atividades enzimáticas, afetando, como conseqüência, o desenvolvimento da planta (Caldiz \& Fernández, 1999).
A alelopatia vem se tornando uma linha de estudos de grande interesse para muitos pesquisadores, os quais ao longo dos anos permanecem na expectativa de descobrir novas substâncias, que causam algum tipo de efeito benéfico ou deletério sobre o desenvolvimento de outras plantas ou microrganismos, visando diminuir o impacto ambiental provocado pelos herbicidas sintéticos usados nas culturas (Belz \& Hurle, 2004; Qiming et al., 2006).

As substâncias produzidas pelas plantas são agrupadas em famílias, de acordo com suas similaridades biogenéticas. Essas famílias compreendem os fenóis simples, ácidos orgânicos, aldeídos, lactonas simples insaturadas, terpenos, esteróides, quinonas, flavonóides, taninos, alcalóides, cumarinas, aminoácidos, ácidos graxos, álcoois, polipeptídios, nucleosídeos e muitos outros ainda não identificados (Blum, 1998; Macías et al., 1992 , 2000; Weidenhamer et al., 2004; Nishida et al., 2005).

Há várias suspeitas de que substâncias da classe dos flavonóides possuam propriedades alelopáticas, mas poucas delas foram identificadas. Uma delas é a florizina, encontrada nas raízes da macieira, que causa a inibição do crescimento das plântulas da própria espécie, e alguns de seus derivados são tóxicos para outras plantas (Blum et al., 1991; Boufalis \& Pellissier, 1994).

Os óleos essenciais de uma planta possuem efeitos inibitórios que são caracterizados pela presença de substâncias terpenóides; os monoterpenos são os compostos encontrados com maior freqüência na maioria desses óleos. Os terpenos também podem estar relacionados com a destruição dos tecidos e lesões nas plantas superiores; esses efeitos podem, porém, ser provocados pelos fungos que sintetizam essas substâncias (Almeida, 1988; Friebe et al., 1997). 
O objetivo deste trabalho foi analisar as propriedades alelopáticas e fitoquímicas presentes no extrato metanólico do caule de Pterodon emarginatus (sucupira-branca) e sua ação sobre a germinação e o desenvolvimento da raiz e parte aérea do capim-colonião (Panicum maximum) e, através de métodos cromatográficos e espectrométricos, identificar qual ou quais substâncias são responsáveis por esses efeitos.

\section{MATERIAL E MÉTODOS}

Os solventes químicos usados foram de grau analítico.

\section{Coleta e preparo das amostras}

As amostras de sucupira-branca foram coletadas em uma fazenda pertencente à Universidade Federal de Uberlândia, localizada no municipio de Uberlândia-MG. As amostras foram colhidas em três regiões diferentes, diretamente no campo, onde a planta prolifera naturalmente. No presente estudo, três troncos de plantas de aproximadamente oito anos de idade e DAP (diâmetro à altura do peito) de $15,0 \mathrm{~cm}$ foram colhidos. Os troncos foram cortados na altura, que variou de $25,0 \mathrm{~cm}$ da base até a 1,3 m (DAP). Em seguida, as amostras foram descascadas e transformadas em discos de $2,0 \mathrm{~cm}$, para depois serem lavadas com água e secas em estufa a $40{ }^{\circ} \mathrm{C}$, e, finalmente, picadas e trituradas em liquidificador.

\section{Obtenção do extrato metanólico}

Para obtenção do extrato bruto, foram utilizados aproximadamente $3,00 \mathrm{~kg}$ de pó do material vegetal (caule) e $10 \mathrm{~L}$ de metanol PA, permanecendo em imersão por 10 dias. Esse procedimento foi realizado em temperatura ambiente e com agitações periódicas. Em seguida, o material foi filtrado em funil de placa porosa, e o filtrado obtido foi concentrado em um evaporador rotativo, à pressão reduzida e a $40{ }^{\circ} \mathrm{C}$, resultando um extrato bruto pastoso. Deste extrato foram preparadas soluções nas concentrações de $25,50,75,100,150,200$, 300 e $400 \mathrm{ppm}$, as quais foram utilizadas para bioensaios de germinação em placas de Petri e em casa de vegetação.

\section{Fracionamento do extrato metanólico}

O extrato metanólico bruto foi primeiramente incorporado à sílica-gel em proporções equivalentes, até que a mistura tivesse um aspecto de um pó homogêneo. Em seguida, a mistura foi colocada em uma coluna cromatográfica empacotada com sílica-gel como fase estacionária. Através de análises cromatográficas em camada delgada, foi possivel definir a seqüência dos solventes ou mistura de solventes (fase móvel) a serem usados para separar as primeiras frações do extrato metanólico. Com esse fracionamento, obteve-se um total de oito frações. Para obtenção da fração F1 foi usado hexano; diclorometano para a fração F2; clorofórmio para a fração F3; acetato de etila para a fração F4; acetato de etila/metanol (9/1) para a fração F5; acetato de etila/metanol $(7 / 3)$ para a fração F6; acetato de etila/metanol (5/5) para a fração F7; e metanol para a fração F8. Cada uma dessas frações foi concentrada a vácuo.

\section{Subfracionamento das frações diclorometano e acetato de etila}

As frações extraídas com o solvente diclorometano (F2) e acetato de etila (F4) apresentaram maior porcentagem de inibição sobre a germinação de sementes e o desenvolvimento da parte aérea e raiz da planta do capim-colonião. De acordo com esses resultados, essas frações foram escolhidas para um posterior subfracionamento.

A fração diclorometano foi incorporada à sílica-gel em proporções equivalentes e o subfracionamento foi realizado por cromatografia, utilizando sílica-gel como fase estacionária. Para obtenção da subfração sf1 foi usada a mistura hexano/diclorometano / clorofórmio (2/5/3); diclorometano/clorofórmio (5/5) para a subfração sf3; hexano/diclorometano/clorofórmio (3/6/1) para a subfração sf2; hexano/diclorometano/clorofórmio $(3 / 5 / 2)$ para a subfração sf4; hexano/diclorometano/clorofórmio (4/5/1) para a subfração sf5; e diclorometano para a subfração sf6.

De forma análoga, no subfracionamento do extrato acetato de metila, para obtenção da subfração sf7, foi usado acetato de etila/ clorofórmio/metanol (5/4/1); acetato de etila/ 
clorofórmio/metanol $(4,5 / 4,5 / 1)$ para a subfração sf8; acetato de etila/clorofórmio (5/5) para a fração sf9; e acetato de etila/clorofórmio (6/4) para a fração sf10. Cada uma dessas subfrações foi concentrada a vácuo. Em seguida, foram preparadas, como mencionado anteriormente, as soluções a 200 ppm de todas as subfrações que foram utilizadas nos ensaios de germinação em placas de Petri.

\section{Ensaio de germinação}

Para realizar os ensaios de germinação, primeiramente foi feita a quebra de dormência das sementes de $P$. maximum pré-selecionadas com acido sulfúrico concentrado. Em seguida, elas foram esterilizadas durante dois minutos com hipoclorito de sódio a $10 \% \mathrm{~m} \mathrm{v}^{1}$.

Os ensaios de germinação (para verificação do potencial fitotóxico) foram realizados, em triplicata, com concentrações de 0 (controle), 25, 50, 100 e 150 ppm do extrato metanólico para os bioensaios feitos em placas de Petri (in vitro) e de 0,100, 200, 300 e $400 \mathrm{ppm}$ do mesmo extrato para os bioensaios feitos em casa de vegetação (in vivo), em água destilada. As soluções em diversas concentrações foram preparadas utilizando cerca de $0,200 \mathrm{~g}$ da amostra, primeiramente diluída em $1,00 \mathrm{~mL}$ de solvente $\mathrm{N}, \mathrm{N}$-dimetilformamida, e o volume completado com água. As placas de Petri com papel-filtro foram previamente esterilizadas em autoclave e cada parcela experimental foi constituída de 15 sementes. A terra utilizada nos ensaios in vivo também foi esterilizada em autoclave, sendo cada parcela experimental constituida de 10 sementes. As placas de Petri foram transferidas para câmara de germinação, onde permaneceram por um período de 15 dias, à temperatura de $25^{\circ} \mathrm{C}$ e fotoperíodo de 10 horas. Os testes que foram feitos em condições de casa de vegetação tiveram o mesmo período de germinação e, uma vez que estes foram realizados com o objetivo de estar o mais próximo possivel das condições reais de cultivo, foram realizados à temperatura ambiente e fornecimento de luz solar, com fotoperíodo de aproximadamente 11 horas. Após o periodo de germinação, mediu-se o comprimento do caule e das raízes, para determinação da porcentagem de inibição. Determinou-se, ta mbém, a quantidade de sementes germinadas, para inibição na porcentagem de germinação por efeito da presença do extrato.

\section{Cromatografia gasosa acoplada à espectrometria de massas (CG-EM)}

A CG-EM foi realizada em um aparelho da marca Shimadzu GC-17A/QP 5000. As condições operacionais são mostradas na Tabela 4. A espectrometria de massa foi feita com energia de impacto de $70 \mathrm{eV}$ e foram coletados fragmentos de 40 a $650 \mathrm{Da}$. Na identificação dos compostos foi usada uma biblioteca de espectros de massa acoplada ao aparelho (Wiley 330) e índices de Kovat. O volume injetado foi de $1,0 \mu \mathrm{L}$ e a quantificação se baseou no cromatograma de íons totais (CIT).

\section{Análises estatísticas}

Todas as determinações foram feitas em triplicatas, e os resultados correspondem à média \pm o desvio-padrão da média. As médias das concentrações investigadas, de raízes, caule e germinação, foram analisadas estatisticamente por análise de variância, aplicandose o teste ANOVA, e pelo teste de Tukey de comparações múltiplas, ambos em nível de significância de $5 \%(P<0,05)$. Todas as análises foram realizadas usando o programa Microcal Origin ${ }^{\circledR} 7.5$.

\section{RESULTADOS E DISCUSSÃO}

Na Figura 1 estão representados os resultados dos ensaios de germinação realizados como extrato metanólico de Pterodonemarginatus sobre Panicum maximum em placas de Petri.

Pode-se observar que o extrato bruto de $P$. emarginatus possui atividade inibitória no desenvolvimento da raiz e do caule e na porcentagem de germinação. A inibição da germinação das sementes não foi tão expressiva, ficando aproximadamente em $30 \%$ para a concentração de 50 ppm, sendo mantida para concentrações maiores, não apresentando diferenças significativas $(P<0,05)$. Observa-se também que a germinação foi favorecida com a solução de 25 ppm, a qual inibiu o crescimento do caule mais que o da raiz; contudo, a inibição deles foi praticamente igual com a 


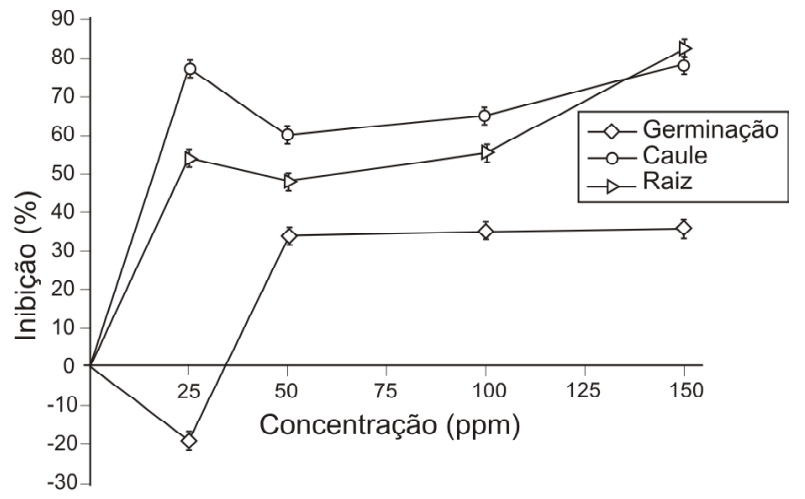

Figura 1 - Efeitos fitotóxicos do extrato bruto de $P$. emarginatus sobre sementes de P. maximum.

solução de 150 ppm, não apresentando diferenças significativas $(P<0,05)$. Nas soluções de 50 e 100 ppm a inibição do caule, também, não apresentou diferenças significativas $(\mathrm{P}<0,05)$ e foi menor que na solução de $25 \mathrm{ppm}$. Na solução de 50 ppm da raiz, a inibição foi menor que na de $25 \mathrm{ppm}$. A partir de $50 \mathrm{ppm}$ a inibição voltou a aumentar até a concentração de $150 \mathrm{ppm}$, quando atingiu o maior indice de inibição, embora não tenha havido diferenças significativas $(\mathrm{P}<0,05)$ para as concentrações de 25 e $100 \mathrm{ppm}$.

Na Figura 2 estão representados os resultados dos ensaios de germinação feitos com o extrato metanólico em casa de vegetação.

Na Figura 2 observa-se que na concentração de 100 ppm a inibição da germinação, do caule e da raiz é aproximadamente igual a $25 \%$, permanecendo praticamente nesse patamar para a raiz e o caule até 200 ppm, diminuindo, porém, para zero na germinação. A partir de $200 \mathrm{ppm}$, aumenta o poder inibitório para caule, raiz e germinação, que alcança os valores de 85,78 e $65 \%$, respectivamente, na concentração de 400 ppm. Não houve diferenças significativas $(\mathrm{P}<0,05)$ em inibição das raízes nas concentrações de 100 e 200 ppm.

As Figuras 1 e 2 sugerem que o extrato bruto de $P$. emarginatus apresenta propriedades fitotóxicas tanto nos ensaios in vitro quanto naqueles in vivo, mas nestes foi requerida concentração bem maior que naqueles, provavelmente pela ação dos microrganismos presentes nos solos que absorvem e decompõem os compostos fitotóxicos.

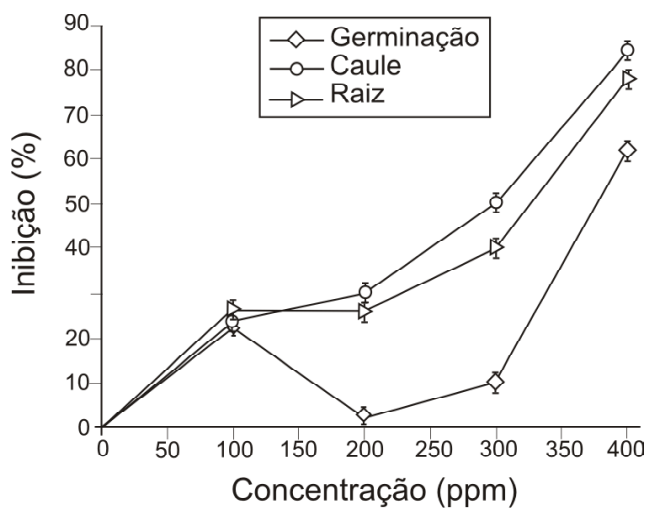

Figura 2 - Atividade inibitória do extrato bruto de P. emarginatus sobre $P$. maximum em casa de vegetação.

Na Figura 3 estão representados os resultados dos ensaios de germinação das frações que mostraram inibição na concentração de $200 \mathrm{ppm}$.

As frações que mais inibiram o crescimento da raiz foram obtidas com diclorometano (fração 2) e com acetato de etila (fração 4), alcançando a inibição os valores de 70 e $77 \%$, respectivamente. A fração acetato de etila/metanol (9/1, v/v, fração 5) apresentou inibição entre 30 e $45 \%$ na germinação das sementes e no desenvolvimento de caule e raiz. A fração acetato de etila/metanol (7/3, v/v) (fração 6) teve inibição expressiva apenas sobre a germinação das sementes (65\%). A inibição da fração acetato de etila/metanol (5/5, v/v) (fração 7) foi abaixo de $30 \%$. A fração obtida com metanol (fração 8) apresentou baixa taxa de inibição no

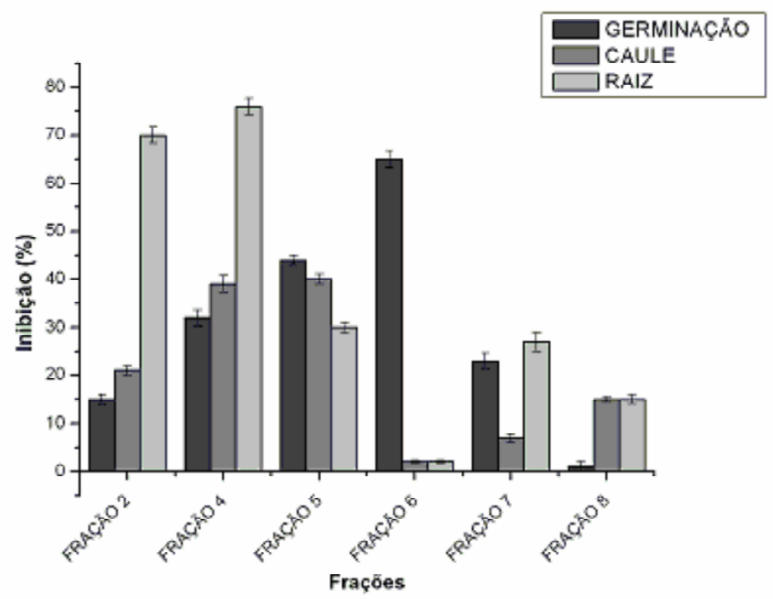

Figura 3 - Efeitos fitotóxicos das frações de P. emarginatus sobre $P$. maximum em placas de Petri. 
desenvolvimento do caule e da raiz e na germinação das sementes. As frações que mais mostraram inibição no crescimento da raiz e/ ou do caule (frações 2 e 4) foram escolhidas para um segundo fracionamento e obtenção de subfrações (sf). As frações 1 (hexano) e 3 (clorofórmio) não apresentaram resultados satisfatórios nos ensaios de germinação, mostrando valores de inibição de aproximadamente $0 \%$.

A subfração que apresentou maior inibição no crescimento da raiz foi extraída com a mistura de solvente diclorometano/clorofór mio $(5 / 5, v / v, s f 3)$, e a que apresentou maior inibição no crescimento do caule foi a de acetato de etila/clorofórmio (6/4, sf10). A subfração hexano/ diclorometano/clorofórmio (2/5/ 3 , sf1) estimulou o crescimento da raiz e do caule em aproximadamente 15 e $20 \%$, respectivamente. A subfração hexano/diclorometano/clorofórmio (3/5/2, sf4) inibiu o desenvolvimento do caule e da raiz em menos de $30 \%$. A subfração hexano/diclorometano/clorofórmio $(3 / 6 / 1$, sf2) inibiu o crescimento da raiz em $30 \%$ e do caule abaixo de $15 \%$. Não foi obtida massa necessária nos bioensaios com o subfracionamento usando os outros solventes.

É importante destacar que as subfrações tiveram atividade inibitória menor que as frações que lhe deram origem, surpreendentemente, uma vez que era esperada maior inibição com a separação dos constituintes em subfrações. Certamente essa repartição reduziu a sinergia entre os componentes das subfrações sf2 ou sf4, que propiciava maior inibição.
Os compostos presentes na subfração sf3, que apresentou maior atividade, foram identificados por espectrometria no infravermelho com transformada de Fourier (IVTF) e cromatografia gasosa acoplada à espectrometria de massas (CG-EM).

Na Figura 4 é apresentado o espectro IVTF do extrato diclorometano/clorofórmio (1/1, v/v).

A análise das principais bandas é apresentada na Tabela 1 .

A análise das bandas desta tabela permite concluir que o extrato diclorometano/clorofórmio contém substâncias com grupos hidroxila, anel aromático, grupos alifáticos, carbonilas, grupos $\mathrm{C}=\mathrm{C}$ e ligações $\mathrm{C}-\mathrm{O}$ de álcoois, éteres ou ésteres.

Na Tabela 2 são apresentados os compostos voláteis mais abundantes no extrato diclorometano clorofórmio, obtidos por CG-EM.

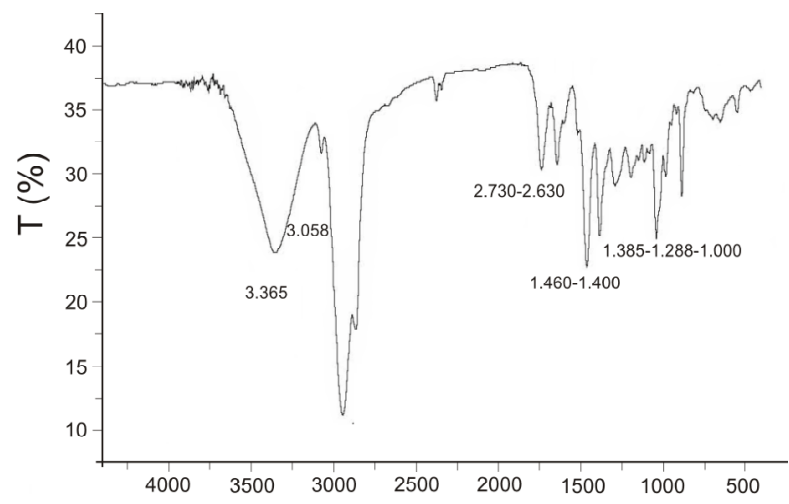

Figura 4 - Espectro no infravermelho do extrato diclorometano/ clorofórmio $(1: 1, \mathrm{v} / \mathrm{v})$.

Tabela 1 - Atribuição das principais bandas do espectro IVTF do extrato diclorometano/clorofórmio (5/5, v/v)

\begin{tabular}{|l|l|}
\hline \multicolumn{1}{|c|}{ Número de onda $\left(\mathrm{cm}^{-1}\right)$} & \multicolumn{1}{c|}{ Atribuições } \\
\hline Banda $3.365 \mathrm{~cm}^{-1}$ & Deformação axial $\mathrm{O}-\mathrm{H}$, deformação axial em hidrogênio intermolecular. \\
\hline Banda $3.058 \mathrm{~cm}^{-1}$ & Deformação axial do $\mathrm{C}-\mathrm{H}$ de aromático. \\
\hline Banda $2.942 \mathrm{~cm}^{-1}$ a $2.865 \mathrm{~cm}^{-1}$ & Deformação axial do $\mathrm{C}-\mathrm{H}$ em composto alifático. \\
\hline Banda $1.730 \mathrm{~cm}^{-1}$ & Deformação axial de $\mathrm{C}=\mathrm{O}$. \\
\hline Banda $1.635 \mathrm{~cm}^{-1}$ & $\begin{array}{l}\text { Deformação axial: } \mathrm{C}=\mathrm{O} \text { conjug ada e } \mathrm{C}=\mathrm{C}, \mathrm{CH}=\mathrm{CH} \quad-\mathrm{CH}=\mathrm{CH} \text { dos ácidos } \\
\text { carboxílicos, éster, aldeídos, cetonas e alquenos respectivamente. }\end{array}$ \\
\hline Banda $1.460 \mathrm{~cm}^{-1}$ & $\begin{array}{l}\text { Deformação angular de } \mathrm{CH} \text { e } \mathrm{CH} 3 \text {, vibraçôes de esq ueleto envo lvendo } \\
\text { deformação axial das ligações } \mathrm{C}-\mathrm{C} \text { de aromáticos. }\end{array}$ \\
\hline Banda $1.385 \mathrm{~cm}^{-1}$ & Banda de deformação axial do $\mathrm{CH} 3-\mathrm{CO}$. \\
\hline Bandas $1.288 \mathrm{~cm}^{-1} \mathrm{a} 1.000 \mathrm{~cm}^{-1}$ & Bandas de deformação axial de $\mathrm{C}-\mathrm{O}$. \\
\hline
\end{tabular}


Tabela 2 - Compostos mais abundantes da subfração diclorometano/clorofórmio (5/5, v/v)

\begin{tabular}{|l|c|c|}
\hline \multicolumn{1}{|c|}{ Composto } & Tempo de retenção (min) & \% (CIT) \\
\hline 3-penten-2-ona & 4,35 & 4,1 \\
\hline Isopropenil metil cetona & 5,10 & 3,2 \\
\hline ? (M=98) & 7,13 & 13,5 \\
Isopropilbenzeno & 10,05 & 3,6 \\
\hline 1,2,4-trimetilbenzeno & 11,44 & 8,6 \\
\hline Ácido hexadecanóico (ácido palmítico) & 52,40 & 6,9 \\
\hline (E)-3,7,11,15tetrametilexadec-2-en-1ol (trans-fitol) & 57,60 & 13,6 \\
\hline (9E,12E)- octadeca-9,12dienoato de metila (linolelaidato de metila) & 58,17 & 10,9 \\
\hline Ácido (E)-octadec-9enóico (ácido oléico) & 58,31 & 12,8 \\
\hline n.i. & 60,73 & 6,1 \\
\hline n.i. & 60,90 & 7,5 \\
\hline
\end{tabular}

n.i. $=$ não-identificado CIT $=$ cromatograma de íons totais

A análise da Tabela 2 mostra que 44,2\% dos constituintes voláteis presentes no extrato são os ácidos graxos palmítico e oléico, o éster linolelaidato de metila e o alqueno trans-fitol; os alquilbenzenos 1,2,4-trimetilbenzeno e isopropilbenzeno perfazem $12,2 \%$; em menor quantidade aparecem as duas cetonas (isopropenil metil cetona e 3-penten-2-ona, 7,3\%). Significativa é a presença de um composto desconhecido de massa molar $98(13,5 \%)$ e dois outros de massa molar elevada $(13,6 \%)$.

Os compostos apresentados na Tabela 2 confirmam os resultados obtidos pela análise espectroscópica no infravermelho, uma vez que as bandas de vibração de suas ligações foram perfeitamente captadas por essa técnica (Figura 4 e Tabela 1).

Não há referência na literatura da capacidade inibitória de qualquer dos compostos mencionados anteriormente. Seria o caso, portanto, de testar separadamente cada um deles para ver qual ou quais são os responsáveis por essa inibição.

Os bioensaios de germinação realizados em placas de Petri comprovaram que o extrato metanólico do caule da sucupira-branca (Pterodon emarginatus), a $150 \mathrm{ppm}$, apresentou percentual de inibição de $83 \%$ sobre o desenvolvimento da raiz e $75 \%$ da parte aérea e somente $30 \%$ da germinação das sementes do capim-colonião (Panicum maximum). Em casa de vegetação, os resultados de inibição, a uma concentração de 400 ppm, foram de $83 \%$ para o caule, $80 \%$ para a raiz e $63 \%$ para a germinação. Frações do extrato metanólico obtidas por cromatografia de coluna cromatográfica não reproduziram os resultados obtidos com o extrato metanólico. Esse fato sugere que a atividade inibitória depende mais da sinergia entre os vários aleloquímicos presentes do que de poucos aleloquímicos isoladamente. A fração mais ativa (diclorometano/clorofórmio, 5/ 5) é constituída fundamentalmente por alifáticos de cadeia longa: fitol (13,5\%), ácido oléico $(12,8 \%)$, linoleiladato de metila $(10,9 \%)$ e ácido palmítico (6,9\%). Destaca-se também um composto não identificado de massa molar 98 $(13,5 \%)$ e 1,2,4-trimetil e isopropilbenzenos $(12,2 \%)$. As cetonas isoméricas isopropenil metil cetona e 3 -penten-2-ona perfazem $7,3 \%$ dos compostos. Finalmente, dois compostos de massa molar elevada não puderam também ser identificados (13,6\%).

\section{AGRADECIMENTOS}

Os autores agradecem ao Instituto de Química, pelo suporte de infra-estrutura, e à CAPES e CNPq, pelo suporte financeiro.

\section{LITERATURA CITADA}

ALMEIDA, F. S. A. Alelopatia e as plantas. Londrina: IAPAR, 1988. 60 p. (circular, 53). 
ANAYA, A. L. et al. Allelochemicals from Stauranthus perforatus, a Rutaceous tree of the Yucatan Peninsula. Phytochemistry, v. 66, p. 487-494, 2005.

BELZ, R. G.; HURLE, K. A novel laboratory screening bioassay for crop seedling allelopathy. J. Chem. Ecol., v. 30 , n. 1, p. $175-198,2004$

BLUM, U. Effects of microbial utilization of phenolic acids and their phenolic acid breakdown products on allelophatic interactions. J. Chem. Ecol., v. 24, n. 2, p. 685-708, 1998.

BLUM, U. et al. Phenolic acid content of soil from wheat-no till; wheat- conventional till, and fallow-conventional till soybean cropping systems. J. Chem. Ecol., v. 17, p. 10451067, 1991.

BOUFALIS, A.; PELLISSIER, F. Allelopathic effects of phenolic mixtures on respiration of two spruce mycorrhizal fungi. J. Chem. Ecol., v. 20, n. 9, p. 2283-2289, 1994.

BUSS, D. A.; SHUGENG, C. A. O.; MARK, S. B. Flavonoids from Artocarpus ianceifolius Roxb. Nat. Prod. Res., v. 17, n. 2, p. 79-81, 2003.

CALDIZ, D. O.; FERNÁNDEZ, L. Allelopathy as possible strategy for weed control in agriculture and forestry systems. In: MACIAS, F. A. et al. Recent advances in allelopathy. Cádiz: Universidad de Cádiz, 1999. p. 451462.

CHON, S. U. et al. Allelophatic potential in lettuce (Lactuca sativa L.) plants. Sci. Hortic., v. 106, p. 309-31 7, 2005.

EINHELLIG, F. A. et al. Effects of root exudate sorgoleone on photosynthesis. J. Chem. Ecol., v. 19, p. 369-375, 1993.

FRIEBE, A. M. et al. Effects of 2,4-dihydroxy-1,4benzoxazin-3-ones on the activity of plasma membrane $\mathrm{H}^{+}-$ ATPASE. Phytochemistry, v. 44, p. 979-983, 1997.
MACIAS, F. A. et al. Natural products as allelochemicals. I. Potential allelophatic activity of several sesquiterpene lactone models. Phytochemistry, v. 31, p. 1969-1977, 1992.

MACIAS, F. A. et al. Dehydrozaluzanin C: A potent plant growth regulator with potential use as a natural herbicide template. Phytochemistry, v. 54, p. 65-171, 2000.

NEAVE, I. A.; DAWSON, J. O. Juglone reduces growth nitrogenase activity, and root respiration of actinorhizal black alder seedlings. J. Chem. Ecol., v. 15, n. 6, p. $1823-1826,1989$.

NISHIDA, N. et al. Allelopathic effects of volatile monoterpenoids produced by Salvia leucophylla: Inhibition of cell proliferation and DNA synthesis in the root apical meristem of Brassica campestris seedlings. J. Chem. Ecol., v. 31, n. 5, 2005.

PUTNAM, A. R., DUKE, W. D. Allelopathy in agroecossystems. Ann. Rev. Phytopathol., v. 16, p. 431$451,1978$.

QIMING, X. et al. Allelophatic activity of volatile substance from submerged macrophytes on Microcystin aeruginosa. Acta Ecol. Sinica, v. 26, p. 3549-3554, 2006.

RICE, E. L. Allelopathy. 2.ed. New York: Academic Press, 1984. 422 p.

TAWAHA, A. M.; TURK, M. A. Allelophatic effects of black mustard (Brassica nigra) on germination and growth of wild barley (Hordeum spontaneum ). J. Agron. Crop Sci., v. 189, n. 5, p. 298-303, 2003.

WEIDENHAMER, J. D.; ROMEO, J. T. Allelochemicals of Polygonella myriophylla: Chemistry and soil degradation. J. Chem. Ecol., v. 30, n.5, p.1067-1082, 2004. 